\title{
A família dos 'Inácios': práticas de nominação e memória da escravidáo (litoral do Rio Grande do Sul, séculos XIX e XX)
}

\author{
Rodrigo de Azevedo Weimer ${ }^{*}$ \\ ${ }^{1}$ Arquivo Público do Estado do Rio Grande do Sul / Universidade Federal do Rio Grande do Sul, Porto \\ Alegre / RS - Brasil
}

\section{RESUMO}

$\mathrm{O}$ artigo analisa as práticas de nominação adotadas por descendentes de cativos no litoral do estado brasileiro do Rio Grande do Sul, observando três gerações de uma família específica entre os séculos XIX e XX. Foram analisados inventários, testamentos, documentação paroquial e produzidas entrevistas, a fim de reconstituir trajetórias familiares e identificar práticas de nominação. Decompondo-se as denominações em prenomes, sobrenomes e tecnonímicos, busca-se ir além dos vínculos verticais que os ligavam às famílias senhoriais, enfocando-se também as solidariedades horizontais. Entende-se que essas pessoas imprimiram, em suas formas de nomear, a memória de seus familiares, recriando vínculos com uma ancestralidade cativa, o que pode representar a recriação de sistemas africanos de linhagens. Palavras-chave: ex-cativos; nominação; solidariedades; memória da escravidão; ancestralidade.

\section{The 'Inácios' family: naming practices and memories of slavery (coastal Rio Grande do Sul, $19^{\text {th }}$ and $20^{\text {th }}$ centuries)}

\section{ABSTRACT}

This article analyzes the naming practices adopted by the descendants of enslaved people living along the coast of the Brazilian state of Rio Grande do Sul. It looks at three generations of a specific family over the course of the nineteenth and twentieth centuries. We analyzed inventories, wills, parochial documents, and recorded interviews, which allowed us to reconstruct family trajectories and identify naming practices. We deconstruct denominations into first names, surnames and teknonyms, and we go beyond

DOI: http://dx.doi.org/10.1590/2237-101X02104513

* Historiador do Arquivo Público do Estado do Rio Grande do Sul / Professor colaborador da Universidade Federal do Rio Grande do Sul / Instituto de Filosofia e Ciências Humanas / Programa de Pós-Graduaçáo em História, Porto Alegre / RS - Brasil. E-mail: rod_weimer@hotmail.com. ORCID: https://orcid.org/00000003-1536-6243. 
the vertical ties that linked these people to slaveholding families, focusing also on their horizontal connections. Through their naming practices, these people recorded the memory of relatives, and in doing so re-created links to their enslaved ancestors. These connections can in turn represent the re-creation of African lineage systems.

Keywords: former slaves, naming, solidarities, slavery memory, ancestry.

\section{La familia de los 'Inácios': prácticas de nombramiento y memoria de la esclavitud (litoral de Río Grande do Sul, siglos XIX y XX)}

\section{RESUMEN}

El artículo analiza las prácticas de nombramiento adoptadas por descendientes de esclavos en el litoral del estado brasileño de Río Grande do Sul, observando tres generaciones de una familia específica entre los siglos XIX y XX. Fueron analizados inventarios, testamentos, documentos parroquiales y entrevistas con la finalidad de reconstruir las trayectorias familiares e identificar las prácticas de nombramiento. Descomponiendo las denominaciones en prenombres, apellidos y tecnominicos, se busca ir más allá de los vínculos verticales que ligaban a las familias señoriales, enfocándose también en las solidaridades horizontales. Se comprende que esas personas registraron en sus formas de nombrar, la memoria de sus familiares, recreando vínculos con una ancestralidad cautiva, lo que puede representar la recreación de sistemas africanos de linaje.

Palabras clave: exesclavos; nombramiento; solidaridades; memoria de la esclavitud; ancestralidad.

\footnotetext{
No habló mientras no le preguntaron cuál era su última voluntad.

- Díganle a mi mujer - contestó con voz bien timbrada que le ponga a la niña el nombre de Úrsula. - Hizo una pausa y confirmó -: Úrsula, como la abuela. Y díganle también que si el que va a nacer nace varón, que le ponga José Arcadio, pero no por el tío, sino por el abuelo.
}

Gabriel García Márquez, Cien años de soledad 


\section{Introdução}

Este estudo analisa a inter-relação entre nominação, identidade social e memória entre os descendentes do casal de cativos Manoel Inácio e Felisberta, nascidos nas décadas de 1840 e 1850. Estudam-se os sobrenomes, tecnonímicos ${ }^{2}$ e prenomes por eles utilizados e atribuídos aos seus filhos. Apenas uma vertiginosa redução da escala de observação torna possível a minúcia necessária para tal empreendimento analítico (LEVI, 1992; REVEL, 1998). Apresenta-se a hipótese de que, na denominação das crianças por meio das referências aos ancestrais que passaram pela experiência do cativeiro, aquela família imprimiu no nome - entendido como a marca individual mais específica em um sistema classificatório (LÉVI-STRAUSS, 1970, p. 200) - uma remissão à memória da escravidão.

Analisando, sucessivamente, sobrenomes, tecnonímicos e prenomes utilizados por uma família de cativos, ex-cativos, libertos e livres descendentes da cativa Inácia, da fazenda do Morro Alto, busca-se dar conta do problema apresentado. Porém, a análise dessa família pode apresentar uma contribuição para o entendimento das práticas de nominação em contexto mais amplo. Assim, deve-se discutir sua "representatividade". Se a família estudada náo permite conclusóes necessariamente generalizáveis ao conjunto dos negros do Brasil ou do Rio Grande do Sul, perceber certas lógicas e sistemas valorativos sugere formas historicamente significativas.

A antiga propriedade escravista se encontrava onde, hoje, é a divisa entre os municípios de Osório, distante $105 \mathrm{~km}$ de Porto Alegre, e Maquiné, $23 \mathrm{~km}$ adiante. Compreendia diversas localidades, dentre as quais a de Morro Alto, no atual entroncamento das rodovias BR-101 e RS-407. Os extremos da fazenda eram as localidades de Aguapés e Espraiado, unidas recentemente por um túnel da BR-101 que corta caminho por baixo do morro. A leste, seguia rumo à praia de Capáo da Canoa ${ }^{3}$ ao longo da atual RS-407, cruzando a planície do Faxinal.

\footnotetext{
${ }^{2}$ Por tecnonímico entende-se a prática de atribuir ao filho, como segundo termo de um nome composto, o prenome do pai - ou avós - se legítimo, ou da mãe, se natural. Por exemplo: Pulquéria Felisberta; Angélica Inácia. Provavelmente esta autora se apropriou da noção de tecnônimo empregada por Lévi-Strauss, isto é, formas de nominação que situam os indivíduos em relação a um determinado familiar (WOORTMANN, 1995, p. 304; LÉVI-STRAUSS, 1970, p. 222).

${ }^{3}$ Em meados do século XIX, porto de desembarque negreiro clandestino.
} 


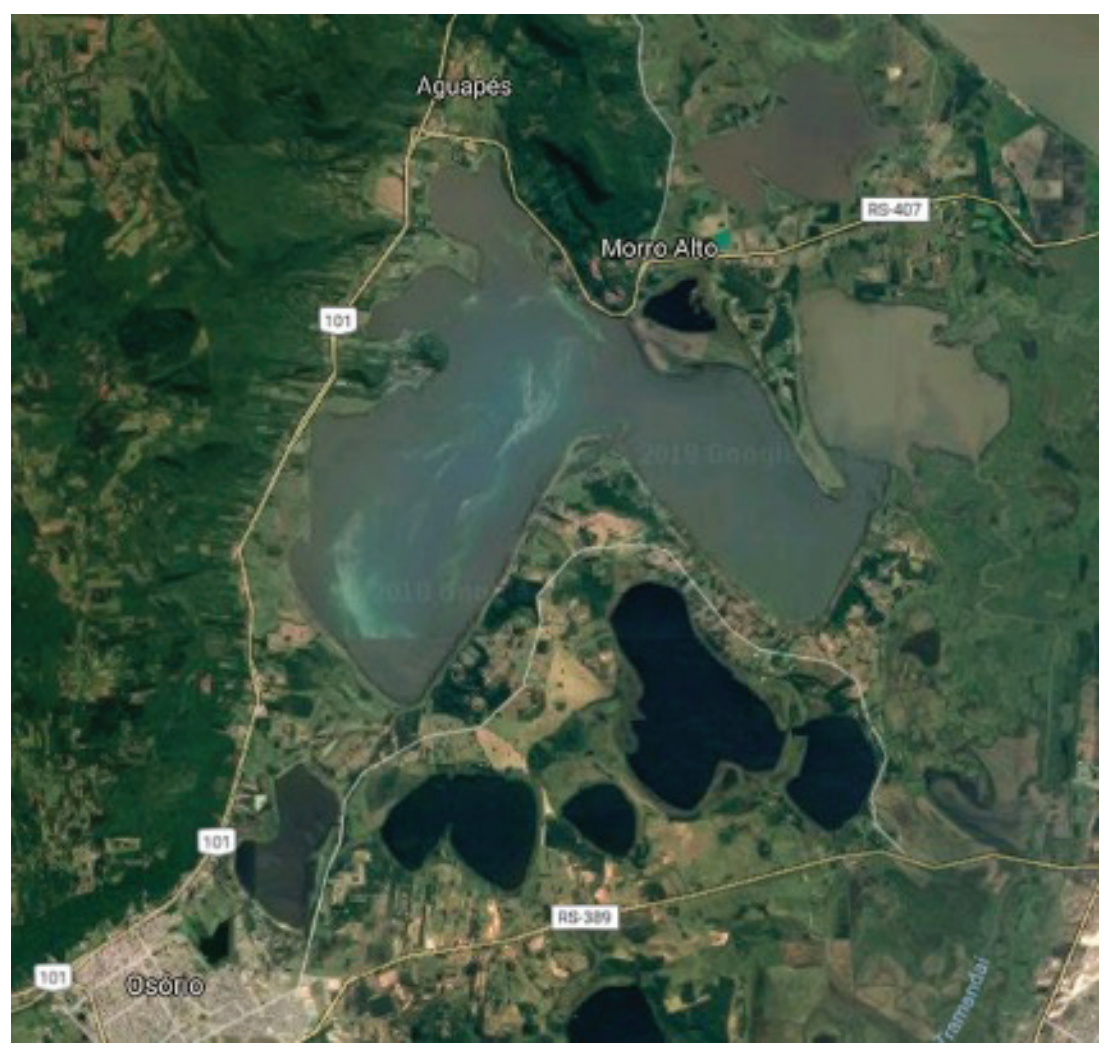

Figura 1: Mapa da região

Fonte: http://maps.google.com.br. Acesso em 10 jan. 2019

Os moradores de Morro Alto - e de localidades conexas ${ }^{4}$ - foram recentemente reconhecidos como "remanescentes de quilombos", e lutam pela regularização fundiária5. Eles descendem dos cativos da fazenda que ali se localizava. No século XIX, Morro Alto era uma das maiores propriedades de Conceição do Arroio, nome antigo de Osório, tanto em extensão como em número de cativos, necessários à lavoura canavieira. Era um empreendimento comum das aparentadas famílias Marques da Rosa, Osório Marques e Nunes da Silveira. Em áreas próximas ao morro plantava-se cana-de-açúcar e em terrenos planos criava-se gado. A maior parte dos cativos dedicava-se à lavoura. No caso das famílias mais prestigiosas na hierarquia interna da escravaria, como a estudada, os homens dedicavam-se às lides campeiras e as mulheres às tarefas domésticas, em vez de ir para o eito (BARCELLOS et al., 2004).

\footnotetext{
${ }^{4}$ Aguapés, Barranceiras, Faxinal, Ribeirão, Ramalhete, Borba, Espraiado, Prainha.

${ }^{5}$ A Constituição Brasileira de 1988 assegura às "comunidades remanescentes de quilombos" o reconhecimento e titularização sobre suas terras. No final da década de 1990, a comunidade de Morro Alto iniciou sua mobilização visando à obtençáo de títulos definitivos de seu território e parcelas expropriadas. Foi naquela ocasiáo, participando do processo de elaboraçáo de um laudo de reconhecimento, que tive meu primeiro contato com essa comunidade.
} 
Inácia foi cativa naquela fazenda. Pertencente ao casal José Marques da Rosa e Isabel Maria Osório, teve numerosa prole ${ }^{6}$. De seus filhos, aqui interessam em especial Angélica e Romão. A primeira teve um filho de nome Manoel, nascido em 1847. Conforme depoimentos, era filho de um integrante da família senhorial. O segundo teve uma filha com Severina, filha de uma africana chamada Tereza. Estima-se que Felisberta, a menina, veio ao mundo em fins da década de 1850 .

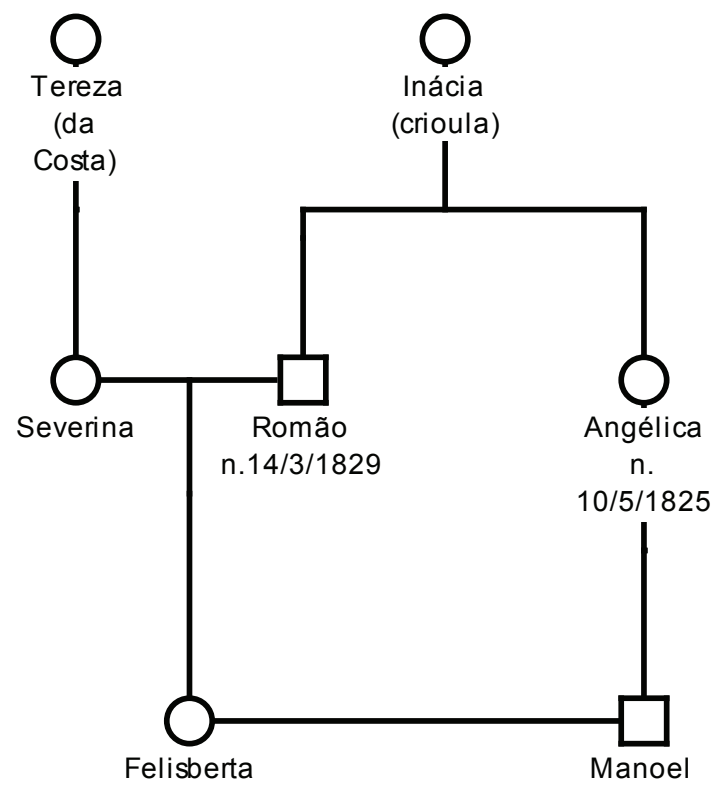

Figura 2: Descendência de Inácia

Elaborado pelo autor. Fonte: BARCELLOS et al., 2004.

O casal de primos - Manoel Inácio e Felisberta (figura 2) - uniu-se, sem matrimônio religioso, em algum momento entre 1881 e 1883 e teve oito filhos. A decisão por enfocá-los decorre do fato de terem vivenciado a transição jurídica do cativeiro à liberdade, vivendo o imperativo de assumir uma identidade civil na sociedade que então se desenhava. Por meio dos nomes empregados por filhos e netos, é possível verificar a persistência de uma memória do cativeiro. A partir do fim do tráfico negreiro, a fazenda do Morro Alto entrou em decadência, pois perdia mercado consumidor para sua aguardente. Seus senhores redirecionaram a criação de gado para outras localidades onde a atividade pudesse ser mais lucrativa, como Capivari e São Francisco de Paula (BARCELLOS et al., 2004). A abolição da escravidão

\footnotetext{
${ }^{6}$ As informaçóes genealógicas sobre a cativa Inácia e sua descendência originam-se de: registros paroquiais microfilmados pela Igreja de Jesus Cristo dos Santos dos Últimos Dias, Centro de História da Família, Microfilme 1391101 (doravante IJCSUD-CHF); relatos orais; Arquivo Público do Estado do Rio Grande do Sul (doravante APERS), Vara de Família e Sucessão da Comarca do Rio dos Sinos, acondicionador 027.0338, ano 1885, inventário 833, de Thomaz Osório Marques; APERS, Vara de Família e Sucessão da Comarca de Santo Antônio da Patrulha, acondicionador 027.0335, ano 1906, inventário 814, de Manoel Inácio Osório Marques.
} 
e a guerra civil de $1893-1895^{7}$ agudizaram esse quadro, de forma que diversos senhores alienaram suas terras aos antigos cativos, por meio de vendas ou doaçôes. É o caso do casal em questão, que adquiriu de Manoel Osório Marques, um neto da ex-senhora, em 1890, o terreno que foi sustentáculo da sua ocupação espacial.

\section{Os usos do sobrenome senhorial}

Gilberto Freyre foi o pioneiro no interesse pelas práticas de nominação utilizadas pelos ex-cativos, uma vez adquirida a liberdade. Sua abordagem, todavia, consolidou uma visão insuficiente, que se arraigou na historiografia brasileira. Segundo ele, os cativos, genericamente, adotaram, na vida livre, os sobrenomes dos antigos senhores, sob a influência do paternalismo e como uma maneira de imitar-lhes formas exteriores de superioridade (FREYRE, 2005 [1933], p. 539-540). Tratar-se-ia, portanto, de mimetizar, em liberdade, as relações hierárquicas estabelecidas pelos ex-senhores. Wissenbach e Lara identificam nessa prática um índice de exercício de poder (WISSENBACH, 1998, p. 253; LARA, 1988, p. 165, 268). Guedes Ferreira (2008, p. 297) chega mesmo a afirmar que o emprego do nome senhorial atesta a submissão dos libertos em relação à família senhorial. No mesmo teor vêm as interpretaçóes de Florentino e Góes (1997, p. 81-92) e de Soares (2009, p. 166-169). Na esteira de Freyre, algumas referências assumem o nome como signo de dependência.

Outros estudos relativizam essa visão, assinalando os significados colocados pelos próprios libertos ao utilizar o nome senhorial, extrapolando o domínio (SCHWARTZ, 1988, p. 237; SLENES, 1996, p. 62; MOREIRA, 2003, p. 293-294; MACHADO, 2008, p. 167). Seu emprego também poderia trazer vantagens relativas, servindo como demarcador da condiçãao de livre e signo de consideração social. Para Xavier (1996, p. 114-116), o compartilhamento de um sobrenome indicava a união de uma coletividade originária de uma mesma escravaria: vínculos entre si, portanto. As observaçóes desses autores convergem com Scott e Zeuske (2004, p. 534), para quem adquirir personalidade legal, entre os ex-cativos cubanos, representou o acesso a um novo conjunto de relaçóes com o processo legal. O direito a um nome representava a possibilidade de ser cidadão.

Não há dúvidas de que o sobrenome dos senhores foi frequentemente utilizado pelos antigos cativos, e que eles manejaram as vantagens que poderia representar um vínculo simbólico com a casa-grande. ${ }^{8}$ A própria família estudada, Marques, é um exemplo. O problema, porém, de limitar-se a essa abordagem é reduzir as práticas de nominação a um de

\footnotetext{
${ }^{7}$ Revolução Federalista.

${ }^{8}$ Naquela localidade, o sobrenome Marques é visto como indício de eventual vínculo biológico com a família senhorial. Utilizam-se também outros sobrenomes, como Silva, Santos, Rosa etc., bem como sobrenomes derivados de tecnonímicos. Há que observar que mesmo para Freyre apenas alguns forros adotaram o nome dos ex-senhores (FREYRE, 2005 [1933], p. 539).
} 
seus aspectos - o sobrenome -, justamente o que realça vínculos com os ex-senhores. Outros aspectos sublinham os laços horizontais.

Os nomes não são utilizados de forma invariável.' Conforme Hébrard, "dentre as maneiras de designar um indivíduo reúnem-se as múltiplas facetas da denominação que, frequentemente, muda com a idade, o tempo, as alianças contraídas ou os eventos” (HÉBRARD, 2003, p. 51). ${ }^{10}$ É, portanto, em relação à natureza do poder simbólico que se pretende acionar que se opta pelo emprego dos sobrenomes senhoriais ou dos nomes costumeiros. Como destacou Antonio Candido, em áreas rurais brasileiras os nomes "oficiais" são utilizados apenas em situações “oficiais”, sendo, no cotidiano, empregados o que ele chama de patronímicos: "Verifica-se tendência para usar, invés do sobrenome, ou além dele, o nome do pai, prolongando o uso arcaico da patronímia [...]. O que sempre houve foi o patronímico, a junção, ao nome próprio, do nome do pai” (MELLO E SOUZA, 2010 [1964], p. 277). ${ }^{11}$

$\mathrm{O}$ autor percebe dois aspectos também verificados no grupo aqui analisado: a) a adição do nome do genitor como componente do nome próprio; b) a utilização em paralelo de nomes oficial e informal, reconhecido - muitas vezes o único conhecido - comunitariamente. Dessa maneira, teríamos, entre os "caipiras", os "nomes de papel”, empregados na oficialidade, tais como em atos e contratos públicos, e outro utilizado em âmbito local (MELLO E SOUZA, 2010 [1964], p. 278). Essas formas alternativas de nomear, aqui denominadas tecnonímicos, foram constatadas pelo antropólogo Norton Corrêa, no Morro Alto, na década de 1970:

A gente do Morro Alto tem jeitos curiosos de botar apelidos nas pessoas. É costume, por exemplo, acrescentar ao primeiro nome, mais outro que é, por sua vez, o primeiro nome da mãe ou do pai. Assim, tem o Antônio "Teresa", o Pedro "Serafina”, o João "Jenuca" (apelido de Januária), o Antônio "Rosa”. [...] Aliás, é sistema antigo e estas denominaçôes emprestadas, com o advento dos registros de nascimento oficiais, os cartórios, muitas vezes terminaram por tornar-se nomes de família (CORRÊA, 1978).

\footnotetext{
${ }^{9}$ Xavier sublinha que o empreendimento proposto por Ginzburg e Poni, de utilização do nome como "fio condutor" de um trabalho de pesquisa deve ser complexificado: dada sua variabilidade, há que considerar os "significados sociais, políticos e culturais" nele latentes, em lugar de, apenas, "fios condutores" de trajetórias individuais (GINZBURG; PONI, 1991 p. 169-178; XAVIER, 2002, p. 5).

${ }^{10}$ Tradução livre. No original: "dans des manières de désigner un individu se rassemblent les multiples facettes de la dénomination qui, souvent, change avec l'âge, le temps, les alliances contractés ou les événements".

${ }^{11} \mathrm{O}$ autor sintetiza com o termo patronímico as características da forma alternativa de denominaçáo aqui designada como tecnonímico, conforme a terminologia de Ellen Woortmann (1995, p. 304). O termo patronímico foi empregado, também, por Zonabend (1995 [1974-1975]), mas para se referir ao que denominamos em português como o sobrenome paterno, e assim ele é empregado aqui.
} 
É provável que a ênfase dada pela historiografia brasileira aos sobrenomes deva-se a um problema de fontes. É claro que em fontes oficiais - às quais geralmente se tem acesso - aparecerão as formas oficiais de nomear. Essa escolha, todavia, não é inócua, pois tende a ocultar a existência de laços horizontais inter e intrafamiliares. Formas alternativas de nomear virão à tona através de fontes orais ou de raros indícios a serem minuciosamente perseguidos em fontes escritas por pesquisadores que os tenham como foco de seu olhar.

O caso das Antilhas francesas oferece um contraponto ao exemplo brasileiro. Ao contrário do Brasil, onde os sobrenomes foram escolhidos de maneira informal, ${ }^{12}$ lá foram atribuídos, pela administração colonial, nomes tomados do repertório da Antiguidade Clássica. Tratava-se, justamente, de impedir que utilizassem os sobrenomes senhoriais, para manter uma distância. Muitos ex-cativos preferiram ser identificados por aspectos como idade, prenome, prenome materno, paterno feminizado ou nome do local onde trabalhavam, recusando uma imputação oficial (COTTIAS, 2003, p. 169-171).

Coloca-se, pois, uma questão: por qual razão os libertos brasileiros, livres de constrangimentos para adotar sobrenomes, teriam escolhido justamente aqueles de seus ex-senhores, enquanto os antilhanos, levados a adotar nomes instituídos pelas autoridades coloniais, procuraram empregar aqueles mais próximos às suas vivências culturais? $\mathrm{O}$ paralelo sugere que nossas conclusôes podem encontrar-se, em parte, distorcidas pelo recorte usualmente dado à questão. A historiografia brasileira tem muito a ganhar se se dedicar ao estudo das formas de identificação que fogem à oficialidade - e que eventualmente eram preferiveis aos nomes "oficiais", os sobrenomes.

\section{Os usos dos tecnonímicos}

No dia 14 de junho de 1937, Rosalina, filha de Felisberta e bisneta de Inácia, escreveu uma carta a sua máe. Ditou àquele que por ela redigia a missiva seu nome como Rosalina Felisberta Inácia: agregou os nomes da mãe e da bisavó. Na mesma ocasião, sua filha Ercília dirigiu versos a sua madrinha Angélica, assinando como Ercília Inácia Marques, imprimindo ao seu o nome da avó de sua avó. ${ }^{13} \mathrm{~A}$ adoção do nome ancestral como parte da identificação pessoal foi recorrente naquela família, bem como na comunidade na qual se insere.

Também Manoel, filho de Angélica, foi por diversas vezes referido como Manoel Inácio, ainda na vigência da escravidáo. Alforriado em 1884, quando foi mencionado apenas como

\footnotetext{
${ }^{12}$ Essa informalidade pode ocultar, porém, o uso costumeiro de sobrenomes entre os cativos ainda sob a vigência da escravidão. Parte dos sobrenomes adotados informalmente na vida em liberdade era empregada de forma usual durante o cativeiro. Para Engemann (2008, p. 132-139), a adoção de sobrenomes dentro de escravarias era um dos "estágios no caminho da formação comunitária", e não resultava de um ato individual de identificação, mas requeria um reconhecimento coletivo.

${ }^{13}$ Acervo particular de Aurora Inácia Marques, disponibilizado ao autor.
} 
Manoel (SCHERER; ROCHA, 2006), aparece contudo como Manoel Inácio no inventário de sua senhora Isabel Maria Osório, em $1867,{ }^{14}$ e foi padrinho de batismo de cinco crianças na segunda metade do século XIX mediante tal denominação. ${ }^{15}$ Em dois casos foi apontado não apenas com o tecnonímico, como também com o sobrenome Osório Marques, que é o que figura em seu inventário de 1906. Portanto, a ausência de sobrenomes entre cativos deve ser questionada (ENGEMANN, 2008, p. 132-139).

Se o Osório Marques vinculava Manoel ao ramo senhorial/paterno, o Inácio o ligava ao ramo cativo/materno. ${ }^{16}$ Ao mesmo tempo, vinculava a família a um quinhão de terras dos libertos a ela associado: o antropônimo metamorfoseava-se em topônimo. Entre os sitiantes estudados por Woortman, em Sergipe do século XX, a utilização do tecnonímico remete não apenas ao pai biológico, como ao sítio familiar (WOORTMANN, 1995, p. 30). Assim se dá na comunidade onde Manoel Inácio viveu. $\mathrm{O}$ território é parcelado por segmentos familiares: terra dos "Terezas", dos "Ilórios”, dos "Inácios” etc.

Os tecnonímicos identificavam ramos familiares, mas também apontavam para o pertencimento comunitário e para a persistência de formas êmicas de denominação (BARCELLOS et al., 2004, p. 219). Gutman (1976, cap. 6), referindo-se aos Estados Unidos escravistas, observa que identidades sociais que extrapolam o vínculo com os senhores de cativos eram ressaltadas pela adoção de nomes oriundos da própria família de cativos. Em estudo anterior observei que essas formas de composição de prenomes evidenciam, da parte dessas famílias, um esforço por construir ancestralidades no Novo Mundo, e vínculos de pertencimento e identificação com os familiares (WEIMER, 2008, p. 320-332). Hebe Mattos observa que a formação de uma comunidade escrava passou pela ressignificação do sistema de linhagens (MATTOS, 1998, p. 145). A nominação desempenhou papel central nesse processo.

Felisberta, prima e esposa de Manoel Inácio, aparece em alguns registros de batismos de seus filhos com o tecnonímico de sua mãe, Severina. No entanto, após o falecimento de seu marido, substituiu o tecnonímico materno pelo da avó paterna. Felisberta era, não há dúvidas, uma "Inácia", já que filha de Romão Inácio, mas, quando viúva, ao manejar o nome de seu pai e não de sua mãe, afirmava-se como esposa de Manoel, também Inácio, com quem não era formalmente casada. ${ }^{17} \mathrm{Da}$ mesma forma, acredito que sua neta, Aurora Inácia

\footnotetext{
${ }^{14}$ APERS, Vara de Família e Sucessão da comarca de Santo Antônio da Patrulha, acondicionador 026.0306, ano 1867, inventário n. 99, de Isabel Maria Osório.

${ }^{15}$ IJCSUD-CHF - Microfilme 1391100.

${ }^{16}$ Silva (2008) estudou os Caetanos, família negra de Itajaí. Ainda que fossem descendentes dos cativos da família Caetano Vieira, o autor indica que o nome adotado decorria da ancestral reverenciada, a "preta Caetana". Quer dizer, ainda que o nome senhorial e o tecnonímico coincidissem, Silva aposta na prevalência do segundo.

${ }^{17}$ Felisberta apresentou-se como Felisberta Inácia Marques nos autos de inventário de Manoel Inácio e também no casamento de seu filho Manoel Inácio Marques Filho. IJCSUD - CHF, Mcf. 1444093, It. 10, Registro Civil do Estado do Rio Grande do Sul, Cartório Distrital de Maquiné, Conceição do Arroio, 5º Distrito, Matrimônios 1914-1928, f. 7v-8, ano de 1915.
} 
Marques da Silva, viúva de Antônio Inácio da Silva - cujo "Inácio" nada tinha a ver com a família de sua esposa; vinha de seu pai, Inácio Damas -, ao usar o tecnonímico assinala, além do laço com o tronco familiar, a legitimidade de seu casamento na Igreja.

A nominação assinala uma noção local de legitimidade, não necessariamente correspondente à dos sacramentos católicos (WEIMER, 2016, p. 52-64). Tal como em Cuba, transmitir um nome à descendência era uma forma de evitar a desvantagem social de uma presunção de nascimento ilegítimo (SCOTT; ZEUSKE, 2004, p. 531). É digno de nota que nem Pulquéria, nem Belizário, filhos de Felisberta e Manoel Inácio com outros pais, eram "Inácios". Já os filhos do casal são todos lembrados, e registrados por escrito, como Angélica Inácia, Raquel Inácia, Rosalina Inácia etc. ${ }^{18}$

Raquel e Ladislau não se casaram. José faleceu ainda criança. Angélica teve um filho sem se casar, e Rosalina, dois. Um deles foi referido como Manoel Rosalina, tendo herdado o tecnonímico de sua mãe, e a outra, Ercília, assinou, como visto, Inácia. Sua tia Mercedes assumiu o nome do esposo, não passando tecnonímicos aos seus filhos, que os receberam da família paterna. Maria, porém, o transmitiu às filhas moças, enquanto os rapazes receberam o tecnonímico "Timóteo" de seu pai. Todos os filhos, e alguns netos, do único filho varão de Felisberta que se casou, Manoel Inácio Filho, são conhecidos como "Inácios" ${ }^{19}$

Mesmo quando o tecnonímico "Inácio" não foi transmitido de geração em geração, a lógica de estabelecer um nome de vizinhança baseado na herança geracional foi mantida. Indagada por mim a respeito de seu nome de solteira, Eva, filha de Mercedes, de "nome de assinatura" Eva Marques Corrêa (do marido), parou para pensar um pouco e, por fim, concluiu por Eva Mercedes Marques, assumindo o prenome materno como tecnonímico. ${ }^{20}$ Mais do que rememorando seu nome de solteira, dona Eva o estava compondo de acordo com a lógica nominal local, acrescentando ao seu o de sua mãe. Da mesma forma, quando perguntada pelo nome de sua mãe, ela respondeu "Mercedes Felisberta do que, rapaz?" ${ }^{21}$ Isso demonstra não haver exatamente uma determinação estrutural acerca do formato dos nomes, mas uma utilização situacional, performática, a partir de um idioma coletivamente compartilhado.

Dona Maria Belizário, referida por sua prima Eva, destacou, com ênfase, que embora utilizasse o nome de seu pai junto ao prenome, tinha sobrenome. Esse esclarecimento era questão de honra: não deu margem a dúvidas de que ele legara sobrenome aos filhos. Embora o nome de assinatura fosse "certinho", só se usava "quando precisava". Já os tecnonímicos eram "só porque queria chamar assim", mas eram usados "toda vida". A fala remete à ne-

\footnotetext{
${ }^{18}$ Conferir figura 3 e quadro ao fim do artigo.

${ }^{19}$ Ver quadro ao fim do artigo.

${ }^{20}$ Entrevista com a senhora Eva Marques Corrêa no dia 12 de março de 2010 no Caconde (RS). Laboratório de História Oral e Imagem da Universidade Federal Fluminense (doravante LABHOI - UFF) Dona Eva tinha 88 anos no momento da entrevista.

${ }^{21}$ Entrevista com a senhora Eva Marques Corrêa no dia 14 de janeiro de 2009 no Caconde (RS) (LABHOI - UFF).
} 
A FAMÍlIA dos 'INÁCIOS': PRÁTICAS DE NOMINAÇÃ̃o E MEMÓRIA DA ESCRAVIDÃO (Litoral do Rio Grande do Sul, SÉculos XIX e XX)

Rodrigo de Azevedo Weimer

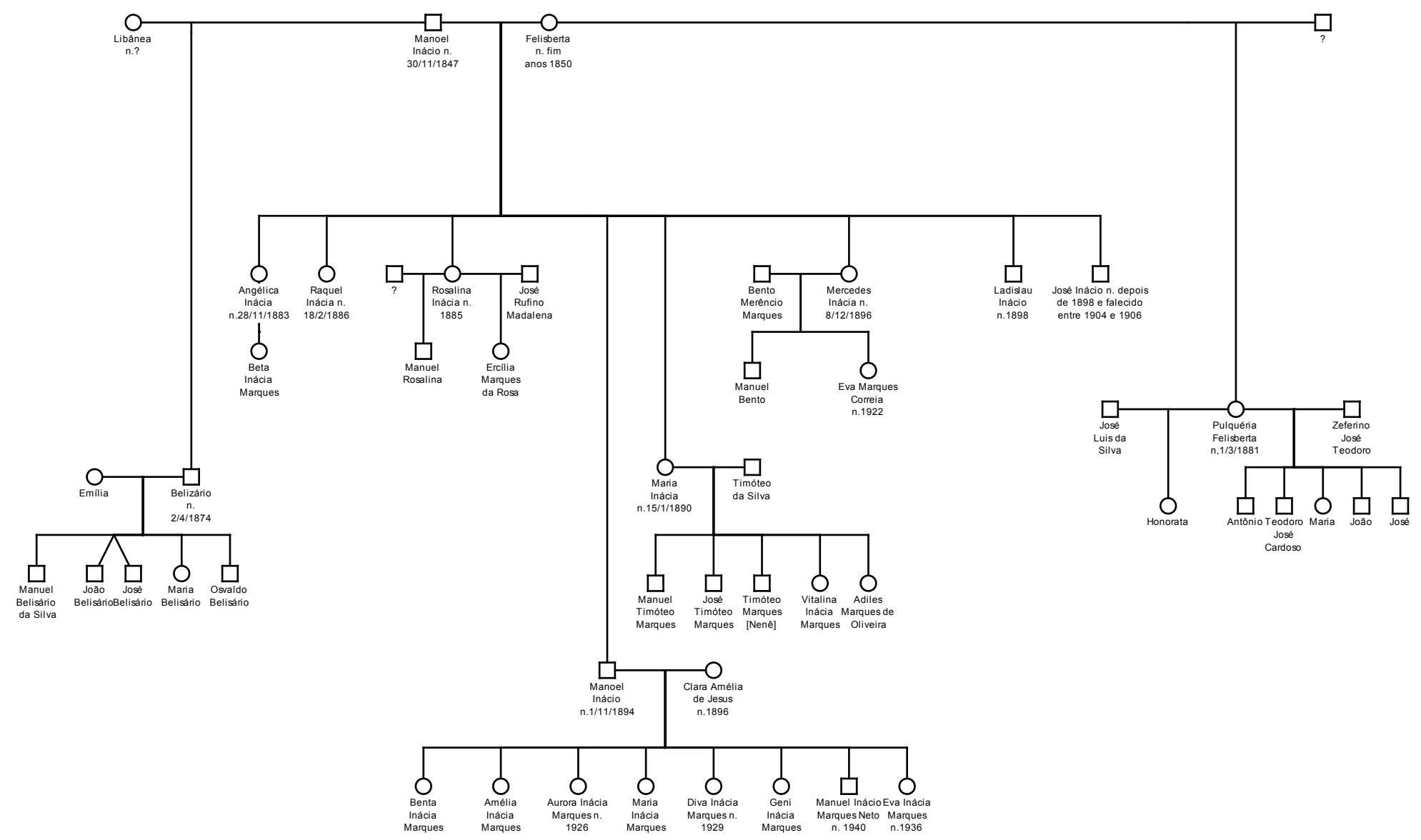

Figura 3: Filhos e netos de Manoel Inácio e Felisberta Elaborado pelo autor. Fonte: BARCELLOS et al., 2004. 
cessidade de ter sobrenomes para o diálogo com a sociedade envolvente e ao uso paralelo de nomes familiares e vicinais. ${ }^{22}$

A identidade como uma família de "Inácios" extrapola o vínculo ciente com a ancestral fundadora da linhagem: Inácia está esquecida no mar da memória. Mas os descendentes de Manoel Inácio e de Romão Inácio, cientes do parentesco entre si, mantêm a designação de "Inácios" justamente em referência aos ancestrais fundadores que passaram pelo cativeiro. Manoel tomou o lugar de Inácia como longínqua ancestral cativa. Uma neta, Diva Inácia Marques Terra - Terra por parte do marido -, optou por legar a seus filhos o sobrenome "Inácio", herdado do bisavô das crianças, em lugar do "Marques", o que demonstra que a reverência ao ancestral superou o orgulho de portar o sobrenome senhorial.

\section{Prenomes e memória da escravidão}

Discutirei agora a composição e os usos de uma marca tão importante quanto o prenome. A "reutilização" de prenomes portados por ancestrais não é novidade para a historiografia sobre o pós-Abolição no Brasil (RIOS, 1990, p. 48-49). Slenes (apud RIOS, 1990, p. 48) constata, na São Paulo cafeeira do século XIX, que pais cativos conferiam a seus filhos os prenomes de pais, tios e avós. Um estudo que observou as práticas de atribuição de prenomes de integrantes da família aos filhos de cativos é o de Hackenberg (1997, p. 97-99). Seus resultados apontam uma proporção de 39\% de nomes tomados de familiares dos cativos na fazenda de Cabussú. No período de liberdade, veremos, encontrei proporçóes superiores, que expressam, contudo, um acompanhamento mais regular dos vínculos patrilaterais: acompanhei não apenas registros de nascimento, mas também relatos de história oral.

Guedes Ferreira, ao analisar uma família de forros (ainda durante a vigência da escravidão), constatou que entre primos de quarta geração, a proporção de prenomes compartilhados era superior a 50\%, afirmando tratar-se de escolhas intencionais que expressavam sentimentos de família (FERREIRA, 2008, p. 297). Infelizmente o autor não desenvolve essa constatação, que sugere nuances em sua interpretação ao expressar, na nominação, mais que vínculos de submissão.

Para cálculo similar, considerei filhos e netos de Manoel Inácio e Felisberta. As informaçôes pesquisadas permitem inferir se os prenomes tomados, nessa família, em empréstimo pelas crianças, se referem a irmãos, pais, tios e avós de seus pais. Porém, considerando que a documentação pode conter lacunas, as referências a prenomes "herdados" devem estar subavaliadas. Considerando a família como um todo, veremos que, de um total de 39 indivíduos, 22 receberam prenomes idênticos aos de familiares de geraçóes anteriores. ${ }^{23} \mathrm{Tal}$

\footnotetext{
${ }^{22}$ Entrevista com a senhora Maria de Oliveira Caetano no dia 23 de janeiro de 2009 em Osório (RS) (LABHOI - UFF).

${ }^{23}$ Conferir quadro ao fim do artigo.
} 
proporção, 56\%, é semelhante à constatada por Guedes Ferreira, mas, no nosso caso, na segunda geração de livres. Desconsiderando Belizário, Pulquéria e os respectivos filhos, que afinal representam "ramos" considerados ilegítimos e nos quais o repertório de familiares a homenagear, por mim conhecidos, cai pela metade, ${ }^{24}$ tem-se um total de 26 indivíduos, dos quais 17 com herança nominal reconhecível. Em outros termos, considerando apenas os filhos de ambos os integrantes do casal, a utilização do stock ${ }^{25}$ nominal familiar conhecido nas geraçôes de filhos e netos de cativos eleva-se para $65 \%$.

Dentre os familiares a quem buscar um prenome, predominam os tios das crianças e dos pais: daqueles 22 indivíduos que receberam prenomes de integrantes da família, dez foram legados por tios e tios-avós. ${ }^{26}$ Apenas dois, um menino e uma menina, adquiriram prenomes de primos ou primos em segundo grau, e uma menina ganhou o prenome de um familiar mais distante. ${ }^{27}$ Nenhuma mulher recebeu o prenome de sua mãe, mas três homens receberam de seus pais. Também entre os que herdaram prenomes de avós há uma predominância da herança nominal masculina: quatro meninos receberam os prenomes de seus avôs e apenas duas garotas foram nomeadas com os prenomes de suas avós.

$\mathrm{O}$ último aspecto pode ser explicado pelo prestígio de Manoel Inácio como patriarca daquele núcleo familiar, que acumulou um pecúlio, trabalhando como carpinteiro nas casas dos grandes fazendeiros da região, que permitiu adquirir um terreno para seus filhos (WEIMER, 2015). O protagonismo na ascensão social que levou aquela família à condição de camponeses negros e a rememorada condição de filho de um senhor de cativos levaram a uma reverência notável por parte da descendência. Homenageava-se a fração da família que "deu certo" ou que construiu as bases da ascensão, fração essa definida como "a família" por excelência (BARCELLOS, 1996, p. 159).

É fato que todos os filhos e filhas de Manoel que tiveram filhos do sexo masculino - inclusive o ilegítimo Belizário - nomearam um filho, até onde pude constatar, o primogênito, com o nome do pai. Isso implica que a repetição nominal entre geraçóes não é resultado do acaso, mas de uma comunhão identitária. ${ }^{28}$ Além disso, guarda semelhanças com os referenciais bakongo e ovimbundo recuperados por Slenes: nesses povos, os primogênitos

\footnotetext{
${ }^{24}$ Desconheço o nome do pai de Pulquéria e tenho contato apenas parcial com a família da mãe de Belizário. ${ }^{25} \mathrm{O}$ termo stock refere-se ao universo de nomes disponível para utilizaçáo por uma coletividade (ZONABEND, 1995 [1974-1975], p. 258).

${ }^{26}$ Conferir quadro ao fim do artigo. Meus resultados contrastam com os de Rios (1990, p. 48-49), que verificou, entre os descendentes de cativos em Paraíba do Sul, a predominância de prenomes de avós e bisavós, em detrimento do de pais e tios. Não sei a que atribuir essa disparidade, mas como analiso apenas uma família de forma mais detida, é possível tratar-se de uma peculiaridade dos "Inácios" ou regional.

${ }^{27}$ Trata-se da avó da esposa do irmáo da mãe da criança (MBWMM, nos termos do sistema inglês de notação de parentesco explicado na nota 35). Segundo as regras de parentesco local, era uma "tia" classificatória.

${ }^{28}$ As famílias internamente empregam apelidos para distinguir homônimos. Manoel Inácio Filho era chamado de Deodício e Manoel Inácio Neto, de João. Aurora Inácia, afilhada de Aurora Conceição, é chamada de Doca. A expectativa pela reiteração de papéis sociais assinalada por Bourdieu (2009, p. 280-281) no contexto da Cabília não implica a fusão de identidades pessoais.
} 
costumavam receber o nome do avô paterno (SLENES, 1999, p. 248). Isso sugere que as similaridades decorrem de laços culturais ressignificados.

As sociedades da região do Congo-Angola, de onde veio a maior parte dos cativos do Rio Grande do Sul, se organizavam por sistemas de linhagens. "O culto aos ancestrais na África tem um significado amplo, político, social e religioso, especialmente no caso das homenagens feitas aos 'ancestrais fundadores' que, como os africanos dizem, 'deram origem a nossa vida e nos trouxeram às terras onde vivemos"” (SLENES, 1999, p. 243). Nossos dados sugerem recriação desses laços por meio da nominação.

Também quantifiquei dentre aqueles prenomes, dos 22 que possuíam herança nominal conhecida, os tomados em empréstimo à linhagem materna ou paterna, ou ainda a ambos os lados. ${ }^{29}$ Desses, 13 (59\%) correspondiam à família da mãe da criança, quatro à do pai, quatro a ambas, e uma a uma familiar mais distante. Tais resultados não surpreendem, já que as genealogias matrilaterais são mais completas que as patrilaterais, o que me leva a desconfiar de uma afirmação genérica de matrilinearidade. Além disso, há que considerar que aquele casal teve um número de filhas muito superior ao de filhos, e desses apenas um deixou descendência. Como nem sempre foi possível apurar as genealogias dos maridos ou dos pais de seus filhos, os stocks nominais também se perderam.

Por fim, realizou-se um levantamento, entre os 22 descendentes de cativos de prenomes reconhecidamente tomados de familiares, da condição jurídica de quem emprestou prenomes aos netos e sobrinhos. O resultado chama atenção: 12 deles, ou 54\%, eram cativos, sendo dois de "ventre-livre", quatro livres e um de condição ignorada, além de três "Josés", prenome presente tanto entre antepassados cativos como em um liberto. ${ }^{30}$ Esses dados indicam uma homenagem significativa de ancestrais que vivenciaram a escravidão, filiação que os vincula a uma memória familiar que remonta ao cativeiro.

Poder-se-ia objetar que não se trata de uma preferência explícita por ancestrais cativos, mas de uma decorrência de a maior parte dos ancestrais disponíveis ter passado pela experiência do cativeiro. No entanto, não havia preferência pelos familiares livres, que correspondiam apenas a $18 \%$ daqueles que cederam prenomes a seus sobrinhos e netos. Em havendo parentes livres/forros, por que se buscou nos cativos o prenome a dar aos seus filhos? Por que não há Serafinas, Clementinas, Herculanos - meios-irmãos de Manoel Inácio, filhos de Angélica Inácia, nascidos livres e prósperos camponeses e artesãos na região ${ }^{31}$ - no repertório nominal familiar? E Luízes e Hermenegildos, familiares também livres?

\footnotetext{
${ }^{29}$ Contempla-se, aqui, duas possibilidades: quando, pelo lado paterno e pelo lado materno existem pessoas com o mesmo prenome, não sendo possível identificar a quem se teve a intenção de homenagear, ou quando um mesmo indivíduo é, simultaneamente, familiar por ambos lados, por causa dos recorrentes casamentos entre primos.

${ }^{30}$ Conferir quadro ao fim do artigo.

${ }^{31}$ É importante observar que Serafina, Clementina e Herculano não receberam o tecnonímico da máe, e sim o tecnonímico e o sobrenome de seu pai, que os legitimou.
} 
O predomínio de ancestrais cativos entre os "doadores" de nomes chama mais atenção quando se leva em conta que o século XIX conheceu uma ética de silêncio quanto à "cor" e à experiência escrava pretérita em momentos de igualdade formal (MATTOS, 1998; MATTOS, 2004). A abolição da distinção entre homens livres e cativos maximizou o processo verificado. Esse silenciamento, contudo, deve ter se dado no espaço público. Mattos sublinha que muitas das famílias mais antigas e estruturadas continuaram a organizarem-se internamente como grupos invisiveis (COHEN apud MATTOS, 2004, p. 88). Permanecia acesa, assim, impressa nos nomes, nas marcas mais individuais de identidade social, a memória do cativeiro, e não como estigma, mas como fator de orgulho promovido pelos pais.

Convém destacar, portanto, a diferença entre ambientes públicos e privados no que diz respeito ao cultivo da memória do cativeiro. Se essa não era sublinhada e destacada em ambientes públicos no pós-Abolição, devido à carga simbólica negativa a ela associada, isso não significa que o cativeiro e as referências a familiares que passaram por essa experiência devessem ser esquecidos. Os diferentes empregos de nomes demarcavam limites entre homenagens particulares e silêncios públicos. As memórias familiares - inclusive aquelas do cativeiro - não apenas foram lembradas, como também acionadas ao demarcar tecnonímicos perenes ao tempo e um stock de prenomes utilizado até, pelo menos, a geração dos netos.

\section{O nome omitido}

Dona Eva relatou uma anedota relativa à dona Júlia, esposa de um fazendeiro, lembrado como alguém desrespeitoso e violento com o campesinato negro da região, chamado Machado. Ela recusava-se a chamar os negros pelo nome e a eles referia-se como "aquele". A representação dessa personagem é negativa: sovina e cruel. Belizário, tio de Eva, nascido de ventre-livre, trabalhava na residência daqueles fazendeiros como carpinteiro - profissão de seu pai. Dona Júlia serviu para os empregados um angu ralo e um café aguado. Como ele não estava comendo, ela perguntou-lhe por que não o fazia e ele respondeu que ainda não havia colocado sua dentadura. Repreendido como "ô aquele", manifestou sua admiração por ela o conhecer desde rapaz novo e ainda não saber seu nome.

Mencionando os negros como "aquele", aquela lhes negava uma característica fundamental da identidade pessoal. Negar-se a comer o alimento de má qualidade e exigir ser chamado pelo prenome era, justamente, uma forma de defender a dignidade. Pollak e Lapierre, remetendo aos campos de concentração, assinalaram ser a subtração do nome próprio um meio de indiferenciação e de desumanização (POLLAK, 2000; LAPIERRE, 2006, p. 367). Mattos (1998), por sua vez, discutiu a homogeneização presente no cativeiro, representada pela referência a um cativo genérico, não nomeado. Quando, na narrativa de dona Eva, tio 
Belizário exigiu da patroa ser chamado pelo próprio nome, estava afirmando uma condição humana menosprezada. Se a experiência degradante do cativeiro não era nominável, sendo lembrada por meio do emprego de pronomes no lugar de prenomes (WEIMER, 2015a), a vida no pós-Abolição era fonte de orgulho, sendo inaceitável a ignorância do nome pessoal e a referência por pronomes demonstrativos.

Talvez Felisberta da Conceição, Felisberta Severina, Felisberta Silveira Marques, dona Felisberta Inácia Marques; quem sabe Manoel Inácio Osório Marques, Manoel Inácio Marques Osório ou apenas Manoel Inácio Marques. Um diferencial entre o cativeiro e a liberdade consistia na prerrogativa de não ser mencionado através da "cor" (MATTOS, 1998). ${ }^{32}$ O nome próprio, atribuído pelos pais, o tecnonímico, herdado dos ancestrais, e o sobrenome representavam formas de afirmação face a "donas Júlias" que tinham a pretensão de menosprezá-los.

"Aqueles", segundo dona Júlia, ou "Belizários", segundo eles e os seus, manipulavam não apenas as categorias nominais visando afirmar sua cidadania, mas também categorias de identificação racializadas. Ser "negro", "moreno" ou "preto” possuíam sentidos específicos e distintos da percepção contemporânea acerca dessas palavras. A categoria "negro" apontava para a indiferenciação, para o anonimato, praticamente para a negação de uma condição humana. Em entrevista a Norton Corrêa, a rainha Jinga Maria Tereza, sobrinha de Felisberta - tia Bebeta - afirmou em 1978: "Neste tempo [referindo-se à época do cativeiro] não se chamava pelo nome: era só nêgo [sic]" (CORRÊEA, 1980).

\section{Considerações finais}

Dégras analisou a recorrência da temática nominal nos romances referentes à América negra. Para a autora, o desenraizamento de nomes africanos e a necessidade de adoção de outras formas de nomear suscitou uma "obsessão nominal" na obra literária de nosso continente. A autora apresentou a proposição de que o nome representa uma metáfora da história (DÉGRAS, 2011, p. 43). Embora partindo da literatura, sua proposta extrapola a metáfora literária. $\mathrm{O}$ nome também é uma forma empregada pelos próprios sujeitos sociais para expressar experiências de reelaboração identitária. Assim, não remete apenas às narraçóes escritas, mas também à história vivida pelos atores históricos. Em grupos sociais em que o acesso à palavra escrita é parcial, as formas de expressar essas experiências são feitas através da oralidade e da memória (WEIMER, 2015b, p. 221-251) - e os nomes são um veículo. Dégras (2011, p. 40) interpretou os esforços de renominação como uma tenaz tentativa de restituir uma identidade que desaparecia da memória coletiva.

No entanto, viu-se que por meio da atribuição de nomes de ancestrais às crianças e, através disso, da recriação de laços de pertencimento familiar, os descendentes de cativos de-

\footnotetext{
${ }^{32}$ No entanto, a exigência de não ser discriminado através da "cor" ou de não ver esquecido o nome próprio não implicava a rejeição de uma identidade negra - ainda que não definida através dessa palavra.
} 
safiaram os obstáculos para o desenvolvimento de uma linguagem nominal. A historiografia brasileira, há tempos, tem colocado em xeque a pretensa impotência de afrodescendentes em face da brutalização promovida pelo cativeiro, apontando sua capacidade de compor laços familiares. Mesmo abrindo mão ou não tendo acesso a nomes africanos ou africanizados, os descendentes de cativos no litoral norte do Rio Grande do Sul - tomada essa família como metonímia - recriaram suas ancestralidades. A sucessão de nomes pode ser tomada como texto que fala de experiências históricas, da memória da escravidão e de uma maneira própria de lidar com a historicidade.

Segundo Slenes (1999, p. 53), os cativos do Sudeste tinham "a capacidade de circular ladinamente entre tradiçóes culturais e estratégias identitárias diferentes”. Gilroy (2001) realiza um jogo de palavras entre raízes e rotas - roots and routes, em inglês - a fim de problematizar a relação entre a origem africana e os itinerários tomados na diáspora. Para ele, existe uma tensão entre ambos os aspectos. A África pode não estar presente nos significados - o stock nominal aqui é efetivamente tomado ao santuário católico ${ }^{33}$ - mas em algo mais sutil e profundo: o código pelo qual os nomes são herdados, dispostos e empregados. Seus sentidos "africanos" encontram-se ocultos em "pressupostos fundamentais comuns sobre as relações sociais ou o funcionamento do universo" (MINTZ; PRICE, 2003, p. 29).

Contudo, cabe à historiografia aprofundar e refinar o entendimento sobre esses vínculos ancestrais, em vez de genericamente identificá-los como africanos. Precisamos conhecer com maior minúcia aqueles códigos. Por exemplo, meu estudo indica a necessidade de discutirmos o caráter matrilinear eventualmente legado pelo continente de origem, já que os dados apresentados indicam para uma herança nominal significativa também pelo ramo paterno e por antepassados masculinos. Isso aponta para uma filiação bilateral nos "ramos" da comunidade em questão, conforme já havia indicado a equipe de Daisy Barcellos (BARCELLOS et al., 2004, p. 209-210). Da mesma maneira, há que qualificar o que entendemos por "linhagens", já que no Brasil, ao que meu estudo particularizado indica, elas dificilmente corresponderiam a uma vinculação unilinear com um ancestral comum. Esse, no caso analisado, não é um africano distante e abstrato, mas o fundador de uma "irmandade", uma "gente", como dizem, em território americano. Inácia, e os seus, eram crioulos.

Dona Aurora lamentou, quando realizava minha pesquisa, que hoje em dia os jovens preferiam assistir televisão em vez de ficar conversando com os idosos ao redor do fogo. ${ }^{34} \mathrm{~A}$ fogueira, lugar de circulação de relatos e de reiteração de afetos ainda na primeira metade do século XX, remete ao fogo doméstico dos cativos. Para Slenes (1999, cap. 4), ele cumpriu seu papel na formação de uma identidade compartilhada, ao ligar vivos e mortos. A ancestralidade foi formada, também, pelas práticas de nominação, que articularam laços sociais para além da escravidão.

\footnotetext{
${ }^{33}$ Hébrard (2003, p. 43-47) destaca que, a partir da revolta dos Malês, em 1835, o uso de nomes africanos tornou-se cada vez mais suspeito.

${ }^{34}$ Diário de campo de 19 de novembro de 2010. Visita à casa de dona Aurora Inácia Marques da Silva.
} 


\section{Anexo - Herança nominal na família de Felisberta - séculos XIX e XX}

Os filhos de Felisberta e Manuel Inácio encontram-se identificados por números e em negrito, e seus netos, por letras e em itálico. Foi utilizada a notação de parentesco inglesa ${ }^{35}$. O X representa nomes não-identificados como pertencentes ao estoque nominal familiar. A notação de parentesco separada por “;” indica indivíduos diferentes, a conjunção "e” evidencia o mesmo indivíduo.

\begin{tabular}{|c|c|c|c|c|}
\hline Nome & $\begin{array}{c}\text { Notaçáo de } \\
\text { parentesco } \\
\text { do familiar } \\
\text { de quem se } \\
\text { herdou o } \\
\text { prenome }\end{array}$ & $\begin{array}{c}\text { Grau de } \\
\text { parentesco } \\
\text { do familiar } \\
\text { de quem se } \\
\text { herdou o } \\
\text { prenome }\end{array}$ & $\begin{array}{l}\text { Familiar } \\
\text { paterno, } \\
\text { materno, } \\
\text { ou ambos }\end{array}$ & $\begin{array}{c}\text { Parente } \\
\text { cativo / } \\
\text { ventre-livre / } \\
\text { livre }\end{array}$ \\
\hline 1) Belizário Manoel de Oliveira & $\mathrm{X}$ & & & $\mathrm{X}$ \\
\hline a) Maria Belizário de Oliveira & $\mathrm{X}$ & & & $\mathrm{X}$ \\
\hline b) Osvaldo Belizário de Oliveira & $\mathrm{X}$ & & & $\mathrm{X}$ \\
\hline c) João Belizário de Oliveira & $\mathrm{X}$ & & & $\mathrm{X}$ \\
\hline d) José Belizário de Oliveira & FB; FFB & Tio; tio-avô & Paternos & $\mathrm{L}$ \\
\hline e) Manoel Belizário de Oliveira & FF & Avô & Paterno & $\mathrm{C}$ \\
\hline 2) Pulquéria Felisberta da Silva & $\mathrm{X}$ & & & $\mathrm{X}$ \\
\hline a) Honorata & $\mathrm{X}$ & & & $\mathrm{X}$ \\
\hline b) Antônio & $\mathrm{X}$ & & & $\mathrm{X}$ \\
\hline c) Teodoro & MMZS & $\begin{array}{c}\text { Primo segun- } \\
\text { do }\end{array}$ & Materno & $\mathrm{VL}$ \\
\hline d) Maria & MS; MMS & Tia; tia-avó & Maternas & $\mathrm{C}$ \\
\hline e) João & $\mathrm{X}$ & & & $\mathrm{X}$ \\
\hline f) José & $\mathrm{MB} ; \mathrm{MMB}$ & Tio; tio-avô & Maternos & $\mathrm{C}$ \\
\hline 3) Angélica Inácia Marques & FM e MFZ & Avó e tia-avó & Ambos & $\mathrm{C}$ \\
\hline a) Beta & $\mathrm{X}$ & & & $\mathrm{X}$ \\
\hline 4) Raquel Inácia Marques & $\mathrm{MZ}$ & Tia & Materna & $\mathrm{C}$ \\
\hline 5) Rosalina Inácia Marques & $\mathrm{X}$ & & & $\mathrm{X}$ \\
\hline a) Manoel Rosalina & $\mathrm{MF}$ & Avô & Materno & $\mathrm{C}$ \\
\hline b) Ercília Marques da Rosa & $\mathrm{X}$ & & & $\mathrm{X}$ \\
\hline 6) Maria Inácia Marques & $\mathrm{MZ}$ & Tia & Materna & $\mathrm{C}$ \\
\hline a) Manoel Timóteo Marques & MF & Avô & Materno & $\mathrm{C}$ \\
\hline b) José Timóteo Marques & $\begin{array}{l}\text { MB; MFB; } \\
\text { MMB }\end{array}$ & Tio; tio-avô & Maternos & $\mathrm{C}$ \\
\hline c) Timóteo Marques & $\mathrm{F}$ & $\mathrm{P}$ & Paterno & $?$ \\
\hline d) Vitalina Inácia Marques & MBWMM & Afim & Afim & $\mathrm{C}$ \\
\hline e) Adiles Inácia Marques & $\mathrm{X}$ & & & $\mathrm{X}$ \\
\hline
\end{tabular}

\footnotetext{
${ }^{35}$ Empregando os termos F (pai), M (mãe), D (filha), S (filho), Z (irmã), B (irmão), W (esposa), H (marido). Por exemplo: FMZ: irmã da mãe do pai. Tia-avó paterna. MMB. Tio-avô paterno MMBD: filha do irmão da mãe da mãe. Prima em segundo grau matrilateral.
} 


\begin{tabular}{|c|c|c|c|c|}
\hline 7) Manoel Inácio Marques Filho & $\mathrm{F}$ & Pai & Paterno & $\mathrm{C}$ \\
\hline a) Benta Inácia Marques & $\mathrm{MMB}$ & Tio-avô & Materno & $\mathrm{L}$ \\
\hline b) Amélia Inácia Marques & $\mathrm{MM}$ & Avó & Materna & $\mathrm{VL}$ \\
\hline c) Aurora Inácia Marques & $\mathrm{MMZ}$ & Tia-avó & Materna & $\mathrm{L}$ \\
\hline d) Maria Inácia Marques & FZ; FMZ; MZ & Tia; tia-avó & Ambos & $\mathrm{C}$ \\
\hline e) Diva Inácia Marques & $\mathrm{X}$ & & & $\mathrm{X}$ \\
\hline f) Geni Inácia Marques & $\mathrm{X}$ & & & $\mathrm{X}$ \\
\hline g) Manoel Inácio Marques Neto & $\mathrm{F} ; \mathrm{FF}$ & Pai; avô & Paternos & $\mathrm{C}$ \\
\hline h) Eva Inácia Marques & FZD e MMBD & $\begin{array}{c}\text { Prima e prima } \\
\text { segunda }\end{array}$ & Ambos & $\mathrm{L}$ \\
\hline 8) Mercedes Inácia Marques & $\mathrm{X}$ & & & $\mathrm{X}$ \\
\hline a) Manoel Bento & $\mathrm{MF}$ & Avô & Materno & $\mathrm{C}$ \\
\hline b) Eva Merêncio & $\mathrm{X}$ & & & $\mathrm{X}$ \\
\hline 9) Ladislau Inácio Marques & $\mathrm{X}$ & & & $\mathrm{X}$ \\
\hline 10) José Inácio Marques & $\mathrm{FB} ; \mathrm{MB}$ & Tio & Ambos & $\mathrm{C}$ \\
\hline
\end{tabular}

\section{Fontes documentais}

ARQUIVO PÚBLICO DO ESTADO DO RIO GRANDE DO SUL (APERS). Vara de Família e Sucessão da comarca de Santo Antônio da Patrulha, acondicionador 026.0306, ano 1867, inventário n. 99, de Isabel Maria Osório.

ARQUIVO PÚBLICO DO ESTADO DO RIO GRANDE DO SUL (APERS). Vara de Família e Sucessão da Comarca do Rio dos Sinos, acondicionador 027.0338, ano 1885, inventário 833, de Thomaz Osório Marques.

ARQUIVO PÚBLICO DO ESTADO DO RIO GRANDE DO SUL (APERS). Vara de Família e Sucessão da Comarca de Santo Antônio da Patrulha, acondicionador 027.0335, ano 1906, inventário 814, de Manoel Inácio Osório Marques.

CAETANO, Maria de Oliveira. Entrevista concedida a Rodrigo de Azevedo Weimer (Laboratório de História Oral e Imagem, Universidade Federal Fluminense - LABHOI UFF), Osório (RS), 23 jan. 2009.

CORRÊA, Eva Marques. Entrevista concedida a Rodrigo de Azevedo Weimer (Laboratório de História Oral e Imagem, Universidade Federal Fluminense - LABHOI - UFF), Caconde (RS), 14 jan. 2009.

CORRÊA, Eva Marques. Entrevista concedida a Rodrigo de Azevedo Weimer (Laboratório de História Oral e Imagem, Universidade Federal Fluminense - LABHOI - UFF), Caconde (RS), 12 mar. 2010.

IGREJA DE JESUS CRISTO DOS SANTOS DOS ÚLTIMOS DIAS - Centro de História da Família (IJCSUD - CHF). Microfilmes 1391100, 1391101 - registros paroquiais de 
batismo, casamento e óbito da Freguesia de Conceição do Arroio.

IGREJA DE JESUS CRISTO DOS SANTOS DOS ÚLTIMOS DIAS - Centro de História da Família (IJCSUD - CHF). Microfilme 1444093 - registro civil de matrimônios do cartório de Maquiné.

\section{Referências}

BARCELLOS, Daisy M. Família e ascensão social de negros em Porto Alegre. Tese (Doutorado em Antropologia Social), Museu Nacional, Universidade Federal do Rio de Janeiro, Rio de Janeiro, 1996.

BARCELLOS, Daisy M.; CHAGAS, Miriam de Fátima; FERNANDES, Mariana Balen; FUJIMOTO, Nina Simone; MOREIRA, Paulo Roberto Staudt; MÜLLER, Cíntia Beatriz; VIANNA, Marcelo; WEIMER, Rodrigo de Azevedo. Comunidade negra de Morro Alto. Historicidade, identidade e direitos constitucionais. Porto Alegre: Editora da UFRGS, 2004. BOURDIEU, Pierre. O senso prático. Petrópolis: Vozes, 2009.

CORREAA, Norton. Os negros do Morro Alto - costumes. Correio do Povo, 11 fev. 1978. CORREAA, Norton. Tia Maria Tereza festejou aniversário rememorando momentos de seu passado. Correio do Povo, 8 fev. 1980.

COTTIAS, Myriam. Le partage du nom. Logiques administratives et usages chez les nouveaux affranchis des Antilles après 1848. Cahiers du Brésil Contemporain, 2003, n. 53/54. DÉGRAS, Priska. L'obsession du nom dans le roman des Amériques. Paris: Éditions Karthala, 2011.

ENGEMANN, Carlos. De laços e de nós. Rio de Janeiro: Apicuri, 2008.

FLORENTINO, Manolo; GÓES, José Roberto. A paz das senzalas. Famílias escravas e tráfico atlântico, Rio de Janeiro, c. 1790-c. 1850. Rio de Janeiro: Civilização Brasileira, 1997.

FREYRE, Gilberto [1933]. Casa-grande \& senzala. São Paulo: Global, 2005.

GILROY, Paul. O Atlântico negro. São Paulo: Ed. 34; Rio de Janeiro: Universidade Candido Mendes, Centro de Estudos Afro-Asiáticos, 2001.

GINZBURG, Carlo. A micro-história e outros ensaios. Rio de Janeiro/Lisboa: Bertrand Brasil/ DIFEL, 1991.

FERREIRA, Roberto Guedes. Egressos do cativeiro. Trabalho, família, aliança e mobilidade social (Porto Feliz, São Paulo, c. 1798-c.1850). Rio de Janeiro: Mauad X: Faperj, 2008.

GUTMAN, Herbert. The Black family in slavery and freedom, 1750-1925. New York: Pantheon Books, 1976. 
HACKENBERG, Carla Casper. Familias em cativeiro. Uma negociação entre escravos e proprietários na fazenda Cabussú, Rio de Janeiro (1780-1830). Dissertação (Mestrado em História), Programa de Pós-Graduação em História, Universidade Federal do Paraná, Curitiba, 1997.

HÉBRARD, Jean. Esclavage et dénomination: imposition et appropriation d'un nom chez les esclaves de la Bahia au XIXe siècle. In: Cahiers du Brésil Contemporain, n. 53/54, p. 31-92, 2003.

LAPIERRE, Nicole. Changer de nom. Paris: Gallimard, 2006.

LARA, Silvia H. Campos da violência. Rio de Janeiro: Paz e Terra, 1988.

LEVI, Giovanni. Sobre a micro-história. In: BURKE, Peter (org.) A escrita da História novas perspectivas. São Paulo: Editora da Universidade Estadual Paulista, 1992.

LÉVI-STRAUSS, Claude. O pensamento selvagem. São Paulo: Companhia Editora Nacional, 1970.

MACHADO, Cacilda. A trama das vontades. Negros, pardos e brancos na construção da hierarquia social do Brasil escravista. Rio de Janeiro: Apicuri, 2008.

MÁRQUEZ, Gabriel García. Cien años de soledad. Buenos Aires: Debolsillo, 2006.

MATTOS, Hebe Maria. Das cores do silêncio. Significados da liberdade no Sudeste escravista. Brasil, século XIX. 1. ed. Rio de Janeiro: Nova Fronteira, 1998.

MATTOS, Hebe Maria. Marcas da escravidão. Biografia, racialização e memória do cativeiro na História do Brasil. Tese (Professor Titular em História), Programa de Pós-Graduação em História, Universidade Federal Fluminense, Niterói, 2004.

MELLO E SOUZA, Antonio Candido [1964]. Os parceiros do Rio Bonito. Estudo sobre o caipira paulista e a transformação dos seus meios de vida. Rio de Janeiro: Ouro sobre Azul, 2010.

MINTZ, Sidney; PRICE, Richard. O nascimento da cultura afro-americana. Uma perspectiva antropológica. Rio de Janeiro: Pallas, Universidade Cândido Mendes, 2003.

MOREIRA, Paulo Roberto S. Os cativos e os homens de bem: experiências negras no espaço urbano. Porto Alegre: EST, 2003.

POLLAK, Michael. L'expérience concentrationnaire. Essai sur le maintien de l'identité sociale. Paris: Ed. Métailié, 2000.

REVEL, Jacques (org). Jogos de escalas - A experiência da microanálise. Rio de Janeiro: Editora Fundação Getúlio Vargas, 1998.

RIOS, Ana L. Família e transição (famílias negras em Paraíba do Sul, 1872-1920). Dissertação (Mestrado em História), Programa de Pós-Graduação em História, Universidade Federal Fluminense, Niterói, 1990. 
SCHERER, Jovani; ROCHA, Marcia (coord). Documentos da escravidão. Catálogo seletivo de cartas de liberdade. Acervos dos tabelionatos de municípios do interior do Rio Grande do Sul. Porto Alegre: Arquivo Público do Estado do Rio Grande do Sul/CORAG, 2006.

SCHWARTZ, Stuart. Segredos internos - Engenhos e escravos na sociedade colonial 15501835. São Paulo: Companhia das Letras, 1988.

SCOTT, Rebecca; ZEUSKE, Michael. Le “droit d'avoir des droits”. Les revendications des ex-esclaves à Cuba (1872-1909). Annales. Histoire, Sciences Sociales. 59e année, n. 3, mai-juin 2004.

SILVA, José Bento da Rosa. Caetano e Caetanos. Tradição oral e história (em preto e branco). Itajaí: Edição do autor, 2008.

SLENES, Robert W. Histórias do Cafundó. In: VOGT, Carlos; FRY, Peter. Cafundó: a África no Brasil. Linguagem e sociedade. São Paulo: Companhia das Letras, 1996.

SLENES, Robert W. Na senzala, uma flor. Esperanças e recordações na formação da família escrava - Brasil Sudeste, século XIX. Rio de Janeiro: Nova Fronteira, 1999.

SOARES, Márcio S. A remissão do cativeiro: a dádiva da alforria e o governo dos escravos nos Campos de Goitacazes, c. 1750 - c. 1830. Rio de Janeiro: Apicuri, 2009.

WEIMER, Rodrigo de Azevedo. Os nomes da liberdade. Ex-escravos na Serra Gaúcha no pós-Abolição. São Leopoldo: Oikos / Editora da Unisinos, 2008.

WEIMER, Rodrigo de Azevedo Felisberta e sua gente. Consciência histórica e racialização em uma família negra no pós-emancipação rio-grandense. Rio de Janeiro: Editora FGV, $2015 \mathrm{a}$.

WEIMER, Rodrigo de Azevedo $\mathrm{O}$ que se fala e o que se escreve: produção de presença e consciência histórica em uma família negra no litoral norte do Rio Grande do Sul. Varia História [online], v. 31, n. 55, p. 221-251, 2015b. Disponível em: http://www.scielo.br/pdf/ vh/v31n55/0104-8775-vh-31-55-00221.pdf. Acesso em: 27 jan. 2020.

WEIMER, Rodrigo de Azevedo Os camponeses do Morro Alto. Família e trabalho no litoral norte do Rio Grande do Sul no pós-Abolição (1890-1930). Porto Alegre: FEE, 2016. Disponível em: https:/www.fee.rs.gov.br/wp-content/uploads/2016/01/20160129livro. pdf. Acesso em: 27 jan. 2020.

WISSENBACH, Maria Cristina C. Sonhos africanos, vivências ladinas. Escravos e forros em São Paulo (1850-1880). São Paulo: HUCITEC, 1998.

WOORTMANN, Ellen F. Herdeiros, parentes e compadres. Colonos do Sul e sitiantes do Nordeste. São Paulo: HUCITEC, Brasília: Edunb, 1995.

XAVIER, Regina Célia L. A conquista da liberdade. Libertos em Campinas na segunda metade do século XIX. Campinas: Centro de Memória UNICAMP, 1996. 
XAVIER, Regina Célia L. Tito de Camargo Andrade: religiâo, escravidão e liberdade na sociedade campineira oitocentista. Tese (Doutorado em História), Programa de PósGraduação em História, Universidade Estadual de Campinas, Campinas, 2002.

ZONABEND, Françoise [1974-1975]. Pourquoi nommer? In : BENOIST, Jean-Marie et al. L'identité. Séminaire interdisciplinaire dirigé par Claude Lévi-Strauss, professeur au Collège de France, 1974-1975. Paris: Quadrige / PUF, 1995. 